\title{
Investigation of Machinability Tests for Brass Alloy
}

\author{
Hana Pechováa ${ }^{1, *}$, Václav Koutný $^{1}$, Jiří Faltus $^{2}$ \\ ${ }^{1}$ Czech Technical University in Prague, Faculty of Mechanical Engineering, 16607 Praha 6, Technická 4, Czech Republic, Europe \\ ${ }^{2}$ VÚK Panenské Břežany, Panenské Břežany, 25070, Praha - Východ, Czech Republic, Europe \\ *Corresponding Author: pechohan@seznam.cz
}

Copyright (C) 2014 Horizon Research Publishing All rights reserved.

\begin{abstract}
The Brasses are copper alloys. The main element is zinc brass. The most widespread are $\mathrm{Cu}$ and $\mathrm{Zn}$ binary alloys with different contents of zinc. Binary brass make up a relatively large group of copper alloys in which zinc content varies from 2.5 to approximately $49 \%$. In addition, there brass, which, besides zinc has other elements. These alloying elements give the brass its material properties. According to the zinc content is divided into low, medium and high percentage of zinc brass.
\end{abstract}

Keywords Brass, Lathe, Drilling, Constant Yoke Force, Turning, Chips

\section{Introduction}

In the article investigation of brass alloys is conducted. The exam drilling constant yoke force was made on the materials from the brass. Between tested materials are new alloys of brass sign as 70 and 74, etalon, and other alloys of brass. On these materials was tested drilling constant yoke force. Turning for known shape of the chips was tested only on new materials sign 70 and 74 . The target is to know which of this two new materials have better properties.

\section{Methodology}

\subsection{Material and Methods}

Brasses materials are copper alloys. The main element is zinc brass. The most widespread are $\mathrm{Cu}$ and $\mathrm{Zn}$ binary alloys with different contents of zinc. Binary brass make up a relatively large group of copper alloys in which zinc content varies from 2.5 to approximately $49 \%$. In addition, there brass, which, besides zinc has other elements. These alloying elements give the brass its material properties. According to the zinc content is divided into low, medium and high percentage of zinc brass. Low zinc brass alloy contains up to $30 \% \mathrm{Zn}$. These brass have single-phase structure. It is composed of $\alpha$ phase that has a face centered cubic lattice (FCC). Medium zinc brass alloy contains from $32-39 \% \mathrm{Zn}$.
These brass have a duplex structure that contains phases $\alpha$ and $\beta$. Duplex structure results in good formability in hot conditions. B phase has a body centered cubic lattice (BCC). High brass alloys contain over $39 \%$ of $\mathrm{Zn}$. These brass have the structure mainly composed of $\beta$ phase with a body centered lattice (BCC). B phase at room temperature has greater hardness than the $\alpha$ phase. The increase of zinc content in copper alloys increases their strength, but it decreases corrosion resistance. The corrosion resistance of brass is good for possibility of product function in atmospheric environment. The problem that occur with brass is that they are prone to dezincification in upright acidic or humid environment.[1,2]

\subsection{Methodology of Drilling Constant Yoke Force}

Drilling test of constant yoke force is performed for drilling machine performance and has the advantage that is a relatively quick and simple test. This test is used in the evaluation of machinability, especially when assessing and comparing results obtained with introduction of new environmental alloys into drilling tool design. The evaluation of this test is used for the development of new materials used in development of drilling tools and for their environmental variations, the investigation will result with better machinability. Previously used as an additive alloy lead produces superior properties in drilling operations. But because lead is unsafe, lead will be removed from these alloys and replaced by organic brass alloy. In this investigation a similar effect will be researched in order to obtain performance of the material composed of alloy that has addition of lead. In this test, drill penetration into the material is introduced under constant feed force. Time required for making layers of a constant hole depth is proportional to the machinability of the material examined. Quality of the method depends on proper procedure, the appropriate choice of test conditions. They should be designed in dependence on the properties of the test material. The optimum would be if there was a reliable cut and measured times would vary only by applicable limits. The test is affected by following parameters: material, spindle speed, the weight of the additional weights on a pulley (which affects the magnitude of the force feed during 
drilling), tool dimensions, the depth of the hole, which will be in correlation to measured drilling time. These factors depend on the progress of the test and an optimum result is expected. A comparison of results tests is then possible. Operation times must be within defined satisfactory limits. Measurement is always relative and depends on measurement equipment and operating parameters, results are not comparable if later investigations don't follow a completely identical test condition. The test is performed so that there is penetration of the tool into the test specimen. Penetration of the drill tool does not take place at a constant speed because of material reaction and tool wear, temperature occurrence, vibrations etc. When the force constant feed rate changes the new feel results from the balance and conditions such as: material, drilling depth, tool diameter drill machinability test sample chip . In order to obtain power shift, weights are added. Weights are suspended on a pulley and by using transmission mechanism power feed is obtained [2 ].

\section{Machine}

The investigation of test for drilling constant yoke force is carried out by the "Drilling - milling machine OPTI BF 20 LVARIO", figure 1. Technical possibilities of the machine are: switch for running left and right, electronically adjustable speed, dynamically controlled speed from 100 to $3000 \mathrm{~min}^{-1}$, digital indicator of quill stroke of precision 0.01 $\mathrm{mm}$, all hand wheels are fitted with vernier measurement scale, Guaranteed concentricity is less than $0.015 \mathrm{~mm}$, measured at Pinole the Drill head tilts from $0^{\circ}$ to $\pm 99^{\circ}$ and this allows milling and drilling at different angles.

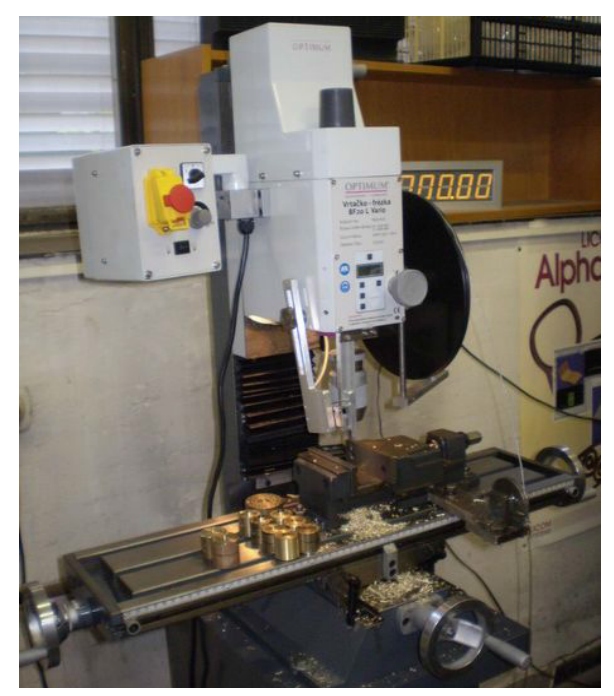

Figure 1. Drill - milling machine OPTI BF 20 VARIO

\subsection{Measuring Equipment}

A device that records the continuous process throughout the drilling is used in this investigation. It is fitted with a constant supply of network, readable display, connectivity to PC via USB and allows to save data in Microsoft Excel software. It is possible to use this measurement device for other machines. Due to its low weight is portable and can be used for testing in job shops in real work conditions. The device works by measuring impulses that come from photocell that is placed on drilling machine. Photocell signal turns on clock time and measurements from the potentiometer simultaneously measuring results and storing them with PC for later processing. The measured values are stored in software Microsoft Excel, where different manipulation of obtained values is possible. For identification of influential parameters different build tables and graphs are available, furthermore evaluation and comparison and of all tested specimens is possible by compiling obtained results. The measurement device was manufactured by ALL System, Ltd..[3,4]

\subsection{Description of the Measuring Device}

The device is based on the Atmel 89C51ED2 which is an IR - gate (photocell sensor) and ADC (analog to digital) converter. $\mathrm{ADC}$ the serial converter with 8-bit resolution. It converts the analog value $2.5 \mathrm{~V}-0.0 \mathrm{~V}$ digital representation in the range 0-255 numbers. CPU receives a signal (start), then the sampling begins (compiling) analog signal is $100 \mathrm{x} / 1 \mathrm{sec}$. and then the measured value is sent as data to the PC. The computer stores the measured data in tables or plots graphs according to investigated result output.[4]

\section{Overview of Specimens}

\subsection{Chemical composition of the Brass Specimens}

Table 1 shows chemical composition of investigated specimens.

\subsection{Properties of Moulds}

The investigated specimens were supplied as extruded rods example 50, 32 and $26 \mathrm{~mm}$ chips were removed and chemical analysis in VÚK. The obtained results are given in Table. 2. Moldings of chemical analysis were done in laboratories at VÚK Panenské Břežany. Figure 2 shows results of drilling time for etalons and investigated materials. 
Table 1. Chemical composition moldings chemical analysis of VÚK Panenské Břežany sro

\begin{tabular}{|c|c|c|c|c|c|c|c|c|}
\hline $\begin{array}{c}\text { Mark by } \\
\text { KOC }\end{array}$ & $\begin{array}{c}\text { Designation } \\
\text { (Pr. pressed) }\end{array}$ & Alloy & $\begin{array}{c}\text { Rp0.2 } \\
{[\mathrm{MPa}]}\end{array}$ & $\begin{array}{c}\text { Rm } \\
{[\mathrm{MPa}]}\end{array}$ & A [\%] & Z [\%] & HBW & HV30 \\
\hline 5 & SMP1 $(32 \mathrm{~mm})$ & CuZn28Si2Mg0.5P0,4 & 198 & 450 & 39 & 32 & 114 & 118 \\
\hline 2 & SMP2 $(32 \mathrm{~mm})$ & CuZn28Si2Mg0.5P0.4Pb & 209 & 464 & 36 & 30 & 116 & 120 \\
\hline 7 & SMP3 $(32 \mathrm{~mm})$ & CuZn28Si2Mg0.5P0.4 & 183 & 396 & 13 & 10 & 127 & 134 \\
\hline 1 & SMPPb2 $(32 \mathrm{~mm})$ & CuZn28Si2Mg0.5P0.4Pb & 199 & 422 & 15 & 11 & 134 & 141 \\
\hline etalon & SPL3L (50 mm) & CuZn28Si2 & 157 & 418 & 27 & - & 117 & 124 \\
\hline 4 & ECO1 & CuZn21Si3 & 220 & 540 & 54 & 54 & 109 & 113 \\
\hline 6 & ECO2 & CuZn21Si3 & 267 & 610 & 42 & 44 & 145 & 157 \\
\hline 8 & ECO3 & CuZn21Si3 & 231 & 558 & 42 & 45 & 130 & 136 \\
\hline 70 & Ms70Si $(50 \mathrm{~mm})$ & CuZn28Si2B & 170 & 412 & 20.3 & 18.7 & $109 \pm 1$ & $114 \pm 3$ \\
\hline 74 & Ms74 (50 mm) & CuZn21Si3ECOBRASS & 235 & 538 & 14.8 & 14.4 & $145 \pm 1$ & $148 \pm 2$ \\
\hline
\end{tabular}

Table 2. Chemical composition moldings chemical analysis of VÚK Panenské Břežany

\begin{tabular}{|c|c|c|c|c|c|c|c|c|c|}
\hline $\begin{array}{l}\text { Serial } \\
\text { number }\end{array}$ & Alloy & $\begin{array}{c}\text { Designation } \\
\text { according } \mathrm{KOH}\end{array}$ & $\begin{array}{l}\text { Rod in } \varnothing \\
\text { in mm }\end{array}$ & $\mathrm{Cu}$ & $\mathrm{Si}$ & $\mathrm{Fe}$ & $\mathrm{Pb}$ & $\mathrm{Sn}$ & $P$ \\
\hline \multirow[t]{4}{*}{1} & $\mathrm{CuZn28Si2B}$ & Ms70Si & 50 & 69.98 & 1.71 & 0.029 & 0.18 & 0.015 & - \\
\hline & & & 32 & 70.02 & 2.07 & 0.027 & 0.17 & 0.015 & - \\
\hline & & & 26 & 69.99 & 1.78 & 0.036 & 0.16 & 0.015 & 0.09 \\
\hline & & & Diameter & 70.00 & 1.85 & 0.03 & 0.17 & 0.02 & 0.09 \\
\hline \multirow[t]{4}{*}{2} & $\mathrm{CuZn21Si3}$ & Ms74 & 50 & 74.94 & 2.92 & 0.013 & 0.054 & 0.012 & - \\
\hline & ECOBRASS & & 32 & 74.94 & 2.81 & 0.024 & 0.055 & 0.012 & - \\
\hline & & & 26 & 74.80 & 2.72 & 0.026 & 0.055 & 0.012 & 0.10 \\
\hline & & & Diameter & 74.89 & 2.82 & 0.02 & 0.05 & 0.01 & 0.10 \\
\hline
\end{tabular}

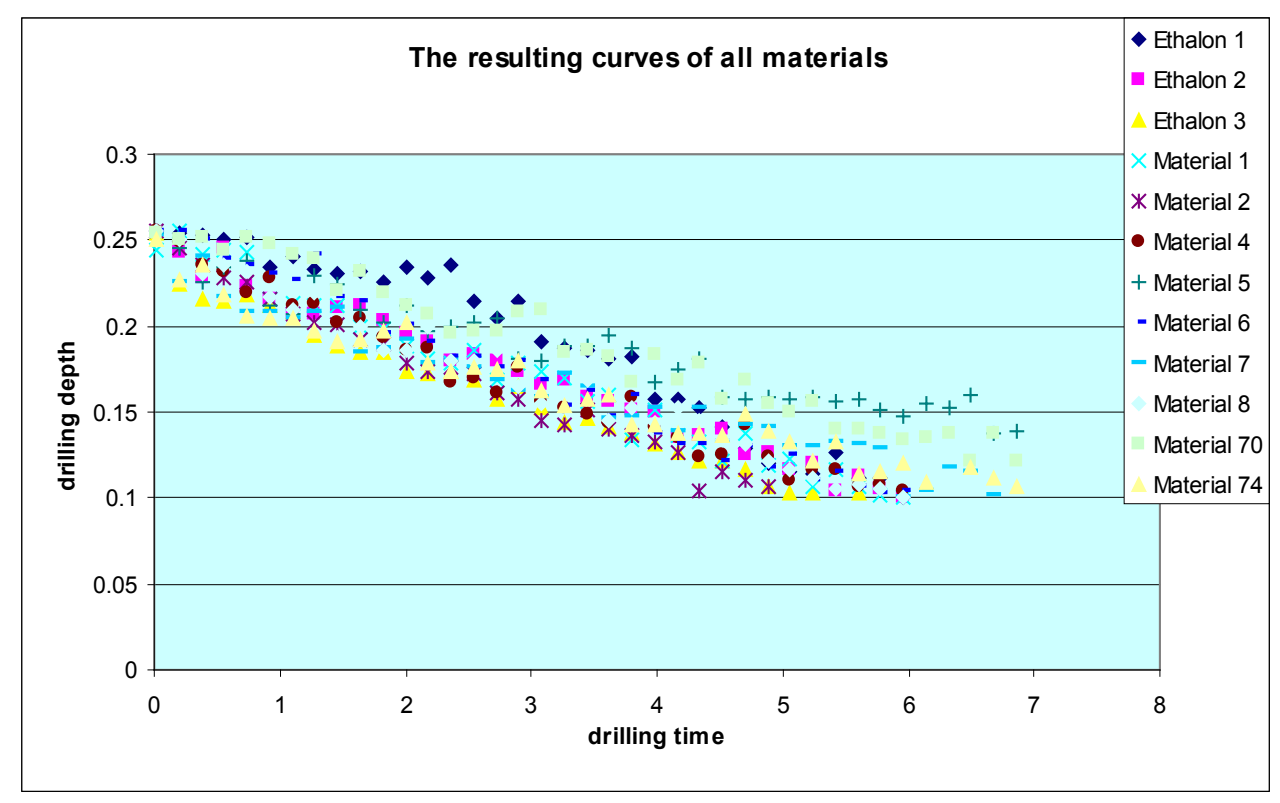

Figure 2. Resulting curves of tested specimens 
Table 3 shows comparative times and standard deviation of conducted investigation.

Table 3. Results of specimens bar no. 70 and no. 74 based on the average times of drilling

\begin{tabular}{|c|c|c|}
\hline Sample & Mean time & Standard deviation \\
\hline 70 & 9.81 & 0.35 \\
\hline 74 & 7.70 & 0.16 \\
\hline
\end{tabular}

\section{Drilling Constant Yoke Force}

Figure 3 show the comparison of new materials, it is apparent that the material č. 74 had shorter drilling time. The difference between the two materials at the time of drilling is small, approximately is a difference of $2 \mathrm{sec}$.

When comparing the times of the individual materials can be seen that the shortest times are samples No.2 and standards. A longest time was the sample No. 5 .

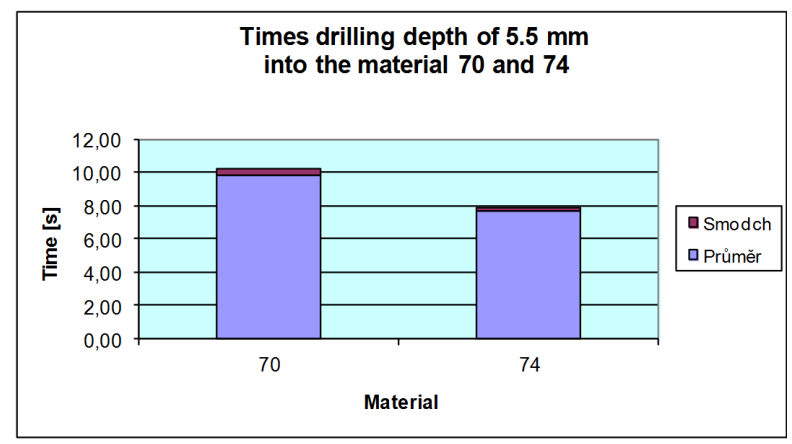

Figure 3. Resulting times for drilled specimens no. 70 and no. 74

\subsection{Note Drilling Constant Yoke Force}

The evaluation test drilling force constant yoke mention three Etalons. They are marked as Etalon (1) Etalon ( 2 ) Etalon ( 3) - SP3L. This is only material which was measured three times, at the beginning, middle and end of the measurement. For each material results are given in a table based on the value of the potentiometer. The values of the potentiometer are recorded by hundredths of a second. However for better insight into results and better overview the authors chose twenty values for construction of resulting graph. Further, there are times when the table has been made to drill depth $5.5 \mathrm{~mm}$ at each measurement. The table contains the average of all measurements and a standard deviation. For all material measurements graphs are drawn. They express the depth of drilling depending on time. Thus, for each material one resulting graph is assembled. In which the curve of measurement is the most important parameter of machinability. For every given measurement depending on material there exists one characteristic curve. Finally a summary graph for all materials is created (graph Fig. 4). Furthermore, in the graph, see Fig. 3 a comparison of the two is shown for new materials 70 and 74 with times of the average bore depth $5.5 \mathrm{~mm}$. Finally, in graph Fig. 4 comparison of all materials according to the time required to drill the depth of $5.5 \mathrm{~mm} .[4,5,9]$

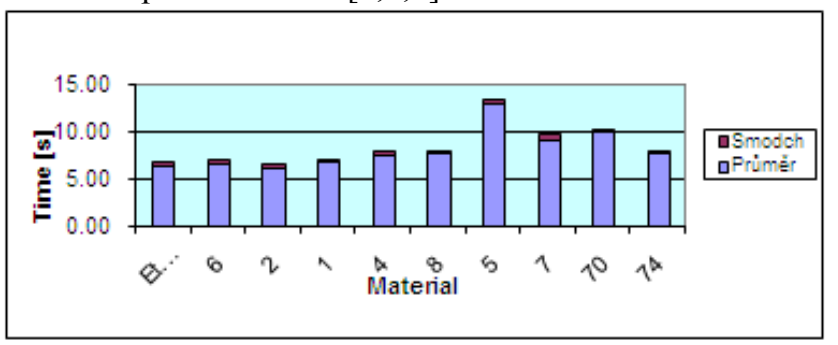

Figure 4. Comparison of all materials according to the time required to drill the depth of $5.5 \mathrm{~mm}$

\section{Turning}

Two specimen bars were investigated of same diameter $\varnothing 50 \mathrm{~mm}$ and length $750 \mathrm{~mm}$. The bar specimens were designated as 70 and 74 , Figure 5.

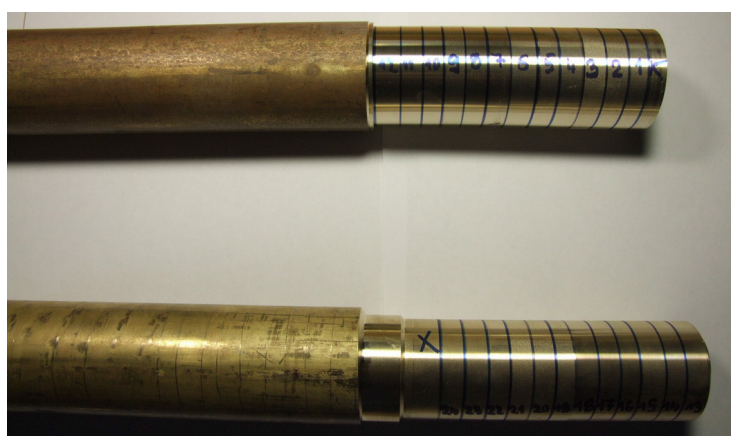

Figure 5. Specimens bar no. 70 and no. 74

On the bar specimen no. 74 the measurement sections were numbered 1 to 12 . On the bar specimen no. 70 the measurement sections were numbered 13 to 24 . On each bar specimen 12 measurement sections were marked and in each region parameters were changed according proposed experimental plan. For each section cutting temperature, surface roughness and formation of chips is investigated.

Cutting temperature, roughness and chip formation were measured on bars (specimens of materials) that are made from organic brass and are labeled 70 and 74 . Measurement was carried out by monitoring the feed rate, cutting speed , cutting depth, speed of rod and tool geometry, especially the blade. The feed rate was $f=0.054,0.074,0.108 \mathrm{~mm} / \mathrm{rev}$. Cutting speed was $v_{\mathrm{c}}=100,200,300,400[\mathrm{~mm} / \mathrm{rev}]$, in some cases it was based on a little above or below specified value. The depth of cut was $a_{\mathrm{p}}=1.5 \mathrm{~mm}$. First measurements were carried out at bar specimen no. 74. For the first six measurements turning tool ISO 2R $2525 \mathrm{~K} 10$ was used. For the next six measurements turning tool SDJCR 2020 K11 MA KT 545 was used. In investigation one condition was always changed and the other was kept constant. The first measurement up to 3 consisted of changing feed. The fourth measurement up to 6 consisted in changing speeds. From the experiment 7 up to 9 turning tools and feed were changed. From 10th to 12 the speeds were changed. with this total of 
12 measurements on bar specimen no. 74 were conducted. The investigation was conducted on a lathe type: SUI 32 A VAC, Figure 6.

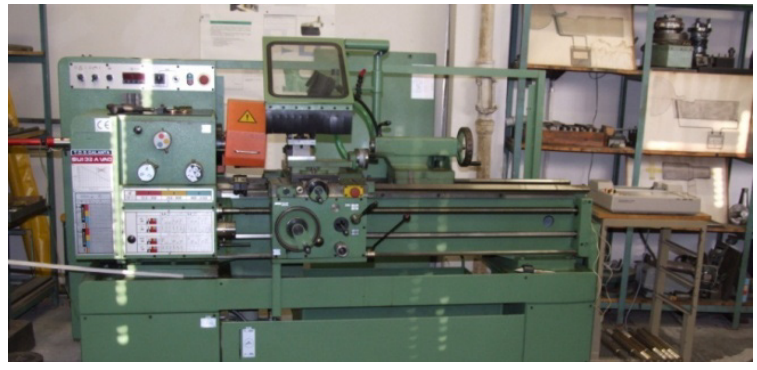

Figure 6. Lathe SUI 32 A VAC

The investigation on bar specimen no. 70 was conducted with the turning tool that finished experiment on bar specimen no.74. Therefore the type SDJCR 2020 K11 -MA KT 545 , which was used for the seventh to 12 measurement on bar specimen no. 74 was used for the first six measurements, i.e. the 13 th up to 18 measurement. Then there was a change of turning tool and measuring continued from 19. to 24th with turning tool ISO $25252 \mathrm{Y} \mathrm{K10}$. Measurements were the same as at 74 bars For the 13th to 15 measurements varied in shift, for the 16 th to 18 measurements the cut was varied for the 19th to 21 measurements feed was varied and for 22 to 24 measurements the speeds were varied.[5,6,8]

\section{Chip formation}

Job shop problems in machining technology usually relate to product quality that is result of appropriate chip removal that is connected to material properties of investigated product. Although the main objective is achieving a clean surface finish and precise dimensions, the issue of the method by which chips are formed is very important topic. The basic chip investigation in machining refers to examination of chips after milling process and developing a good method for chip breaking in order to achieve desired quality. One of the problems in material removal is fast removal from the work area and avoiding chip accumulation in the work area. The chips must be controlled and directed away from the cutting zones, and because of their heat (generated during the machining process) safely removed in order to protect the operator and avoid joining of materials. Nowadays the modern machining create a large amount of particles, and therefore controlled exit splinters are important prerequisite for every machine and this does not depend on how large the volume of machined material is. Good practice in the machining process is use of various materials remove splinters or use of more simultaneously $[8,10]$. Created chips can be monitored and an important factor in their creation is the ability to calculate the resulting temperature and power, because these values affect the quality of chip formation. Temperature affects the process of machining and the achieving a certain level may adversely affect cutting edge of tool material. The forces affecting machining performance and stability of the machining process (vibrations). further durability and safety edge are influenced by the geometry of the cutting edge. In the process of machining metal, material transforms one cutting tool part of the workpiece material and separates it in the form of chips. If more surface of the workpiece is machined, the chips are then closer to the edge and greater increase in shear stress arises. Examining the shape of chips is mainly based on the requirement for a smooth exit chips after the cut, the minimum amount of chips as is shown in Figure 7 and 8 . The examined chips are assigned to certain shape category including chips that determine the direction after formation (breaking of material into chips). When it comes to work on the machine unattended operation is a necessary condition for safe chip forming. The most commonly used assessment form of chips id by ISO classification.

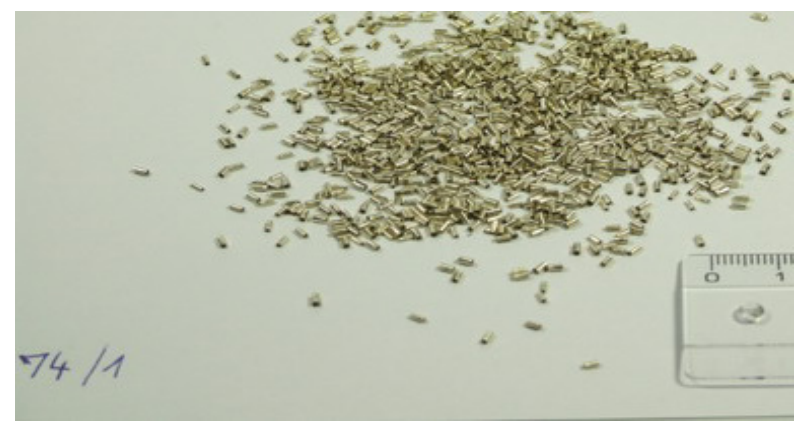

Figure 7. Chip from specimen bar no. $74 \mathrm{CuZn} 21 \mathrm{Si} 3$

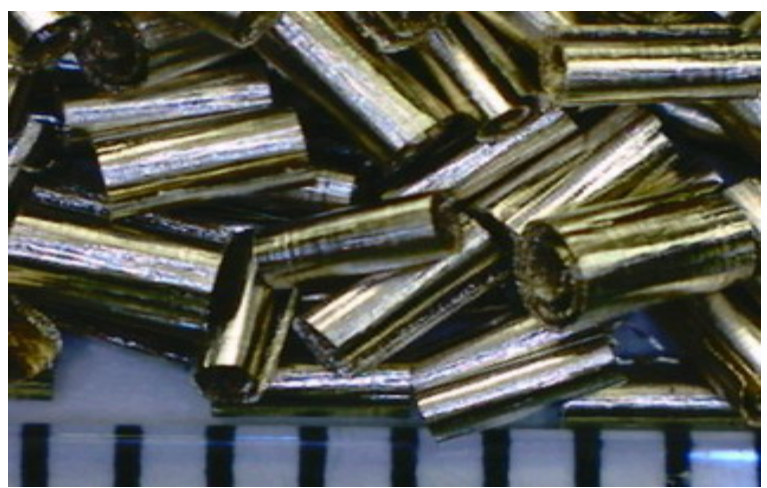

Figure 8. Chips from specimen no. $74 \mathrm{CuZn} 21 \mathrm{Si} 3$

Chips are graded on the basis of classifying particles that arise from measurement done in this research. The resulting chips from each measurement (in this investigation, 24 measurements) to evaluate (classify) according to ISO classifications and assigned the code according to the standard chip classification.

The shapes of chips that are generated by machining process are very important in terms of material consumption, which is always an important economic question. It's important in businesses where staff interferes with the process of machining desiring minimum expenses that might occur in formation of long chips, entanglement of chips into 
the machine or damage. [6]

\section{Description of Measurement}

Two bars specimen no. 70 and 74 are investigated in this research. On each bar 12 sections (measurements) are made in controlled work conditions. Numbered 1 to 12 on the investigated bar 74 and 13 to 24 on the investigated bar 70 . These 24 sections were monitored and after each turning chips were deposited into paper cones for further inspection. Chips of each measurement were filmed by camera "Fuji FinePix S9500". Figure 7 show the chips bar 74 numbered 1.Figure 8 show detail the chips bar 74 numbered 1. Overall views of the formed chip were taken and detailed images were subjected to classification. A code was assigned to chips after each measurement. The chips were also filmed by microscope $[3,9]$.

\section{Conclusion}

New materials designated as 70 and 74 were investigated and their results compared. Results show that material of specimen bar 74 gave better behavior than specimen bar 70 when drilling was measured with constant yoke force. Average drilling time for material 74 was about 2 times shorter than material 70 . When comparing all of the materials investigated it can be seen that the shortest work times were given by samples No.2 and standards. The longest work time was measured for sample No. 5. When examining the cutting temperature of investigated materials the results were very similar. During the control of final roughness, materials differed considerably depending on the used turning tools. Machining of material 70 achieved better surface roughness with the use of turning tool ISO $25252 \mathrm{Y}$ K10. When examining the resulting chips material 74 showed better performance. As material properties are relatively similar it can be concluded that the material 70 developed in the laboratory VÚK in Virgin Brezany is comparable with the material 74 produced by Wieland. It should be emphasized that the material 70 is less expensive. $[1,2,7,10]$

\section{REFERENCES}

[1] Vinger, M., Neckář, F.: Krátkodobé zkoušky obrobitelnosti při soustružení

[2] Faltus, J., : Měd' a slitiny mědi, AVMP - Praha 2000

[3] Mádl, J., Kafka, J., Vrabec M, Dvořák R .: Technologie obrábění první díl - ČVUT 2000

[4] Brychta, Josef; Čep, Robert; Nováková, Jana; Petřkovská, Lenka. Technologie II - 1. díl. Ostrava : VŠB - TU Ostrava, 2007. ISBN 978-80-248-1641-8.

[5] Brychta, Josef; Čep, Robert; Nováková, Jana; Petřkovská, Lenka. Technologie II - 2. díl. Ostrava : VŠB - TU Ostrava, 2008. ISBN 978-80-248-1822-1.

[6] Brychta, Josef; Čep, Robert; Nováková, Jana; Petřkovská, Lenka. Návody do praktických cvičení z Technologie II. Ostrava : VŠB-TU Ostrava, 2009. ISBN 978-80-248-2147-4. $88 \mathrm{~s}$.

[7] Řasa,J.,Gabriel, V., : Strojírenská technologie, Scientia Praha 2005

[8] Fenner, D.: The mini lathe, books limited, 2008 ISBN 978-185-486-25-49

[9] Bray, S.: Metalworking: Tools and techniques, Crowood Press, Limited, 2003, ISBN 978-186-126-57-39

[10] Bray, S.: Milling, Crowood Press, limited, 2004 ISBN 978-186-126-68-04 